\title{
The rise and fall of early oil field technology: The torsion balance gradiometer
}

\author{
RoBIN E. BeLL, Lamont-Doherty Earth Observatory, Palisades, New York \\ R. O. HANSEN, Pearson, deRidder and Johnson, Inc., Lakewood, Colorado
}

Today elementary physics students take for granted such quantities as "big G," the universal gravitational constant. In fact in the late 1700s the value of this quantity was unknown, and the quest to determine it led to some of the earliest geophysical instrumentation. Just after the Revolutionary War in the United States, Cavendish developed the first system to measure the universal gravitational constant, the familiar "big G." Unfortunately, for geologists (at this time still mostly "gentlemen scientists"), this apparatus produced data which were difficult to interpret geologically, and it was far too large and cumbersome for field use. The geologic limitation was that the system only measured the horizontal derivative of a horizontal component of the gravity field, a quantity which by itself is difficult to interpret. Thus no applications of this elegant yet laboratory-bound instrument emerged.

Almost a full century later the great Hungarian physicist Baron von Eötvös designed an instrument which would revolutionize the petroleum industry. As is often the case in revolutionizing technology, Eötvös used "new" fiber technology to significantly reduce the instrument's size and thereby increased portability. Eötvös also added a significant new feature. His master stroke was a design which suspended the weights on the torsion balance at different elevations. This modification made it possible to measure both the horizontal derivative of the horizontal field and the derivative of the vertical field (Figure 1). The vertical derivative was significantly easier to interpret geologically.

Eötvös announced his invention in 1886. His work had been closely followed by the head of the Hungarian Geologic Survey, Von Boeckh, who had been frustrated by his inability to extend the mapping of clearly exposed structures in the mountains beneath the flat-lying plains. Due to prodding by Von Boeckh, Eötvös evaluated the instrument's sensitivity to geologic structures in the early years of this century and published the results in 1908. The first experiments were on a frozen lake, where the depths had been carefully mapped from a boat using a weighted line. The lake gradients could be predicted with confidence. These early successes led to more ambitious efforts to map basement surfaces and, finally, during World War I, to successfully mapping salt domes associated with oil deposits in Germany, Hungary, and Czechoslovakia (Figure 2).

These efforts were followed closely by international oil companies. Anglo-Persian acquired several instruments and began global operations with the torsion balance. Efforts were made in 1914 to import this technology to the United States, but they were delayed by the war. Interestingly, during World War I, E. W. Shaw published a landmark paper in Science outlining the applications of gravity in oil exploration. Meanwhile, new discoveries such as Spindletop were being made largely on the basis of surface anticline structure, seeps, and geologic intuition. Failures (the dry holes) were attributed to a variety of causes including, according to one historian, "the graves of cattle who had died of a hoof and mouth disease."
Following the close of World War I, word of Eötvös' success rapidly reached the United States and by 1922 Eötvös's balances were imported by Shell and Amerada. Late that year, an experimental survey across Spindletop made it clear that the structure could be detected by the instrument. The first discovery by the torsion balance, the Nash Dome, was made in 1924 by Amerada. The map was

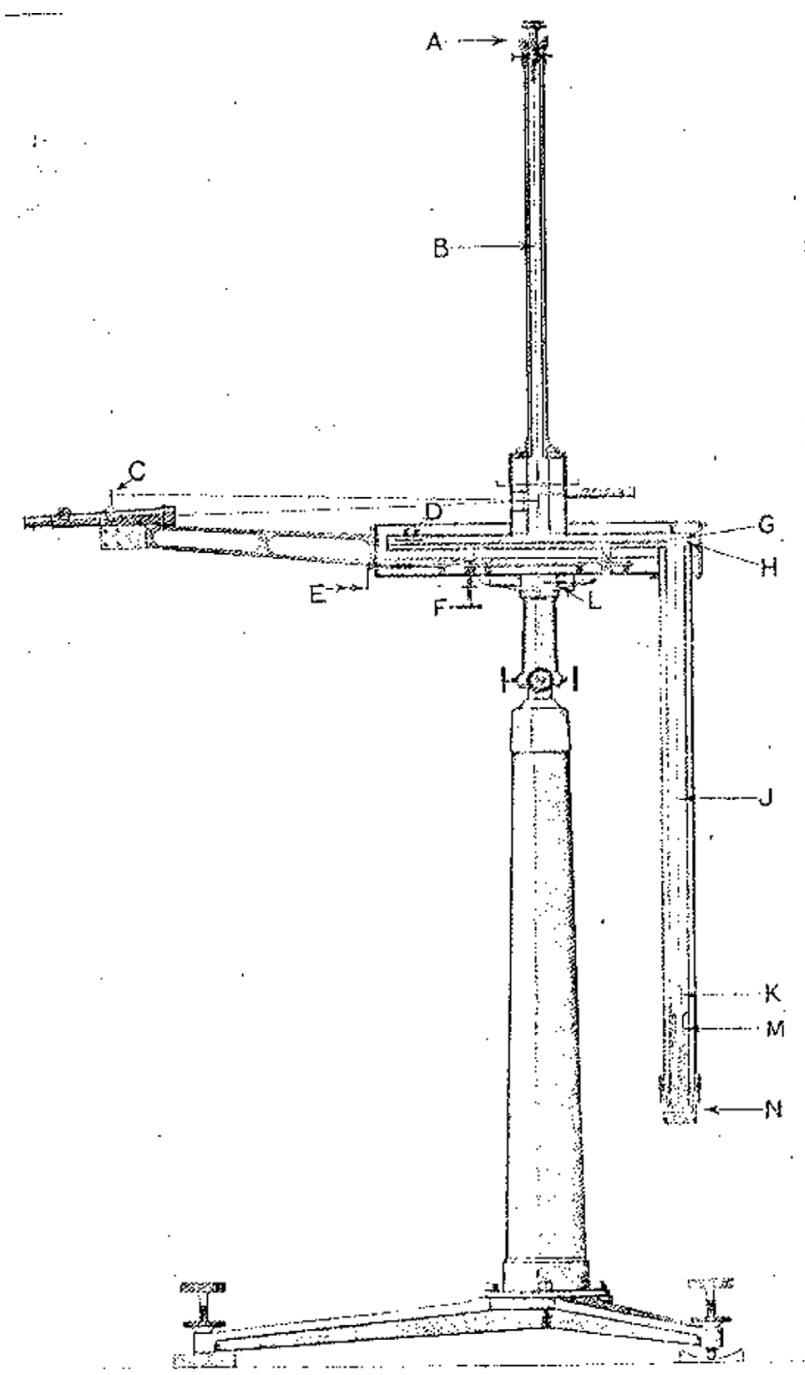

Figure 1. An early torsion-balance instrument $(6 \mathrm{ft}$ tall) which was imported to Britain for a series of demonstrations in London. The gravitational force acting on the small mass on the upper left (point E) was different from the gravitational force acting on the mass on the lower right (point $N$ ). The differing forces caused the rotation of the system about the central axis of the instrument. This rotation, observed through the telescope on the left (point C), was proportional to the local gravity gradients (from "Eötvös Torsion Balance" by H. Shaw and E. Lancaster-Jones, Proceedings of the Physical Society of London, 1923). 


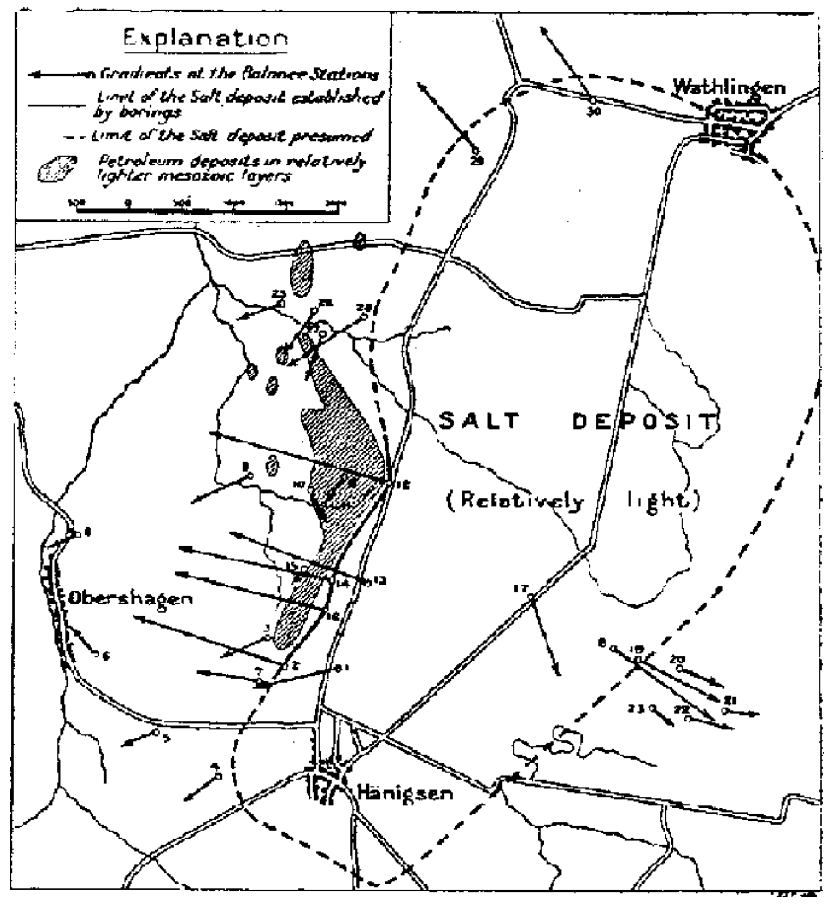

Figure 2. Early map of gravity gradients over a salt dome in Germany. The dashed line outlines the location of the low-density salt dome known from drilling. The arrows indicate the direction and amplitude of the gravity gradient measurement (from "Die bedeutung der drehwage von Eötvös fur die geologische forschnung nebst mitteilung der ergbnisse einiger messungen" by W. Schweydar, Zeitschrift fur praktische Geologie, 1918).

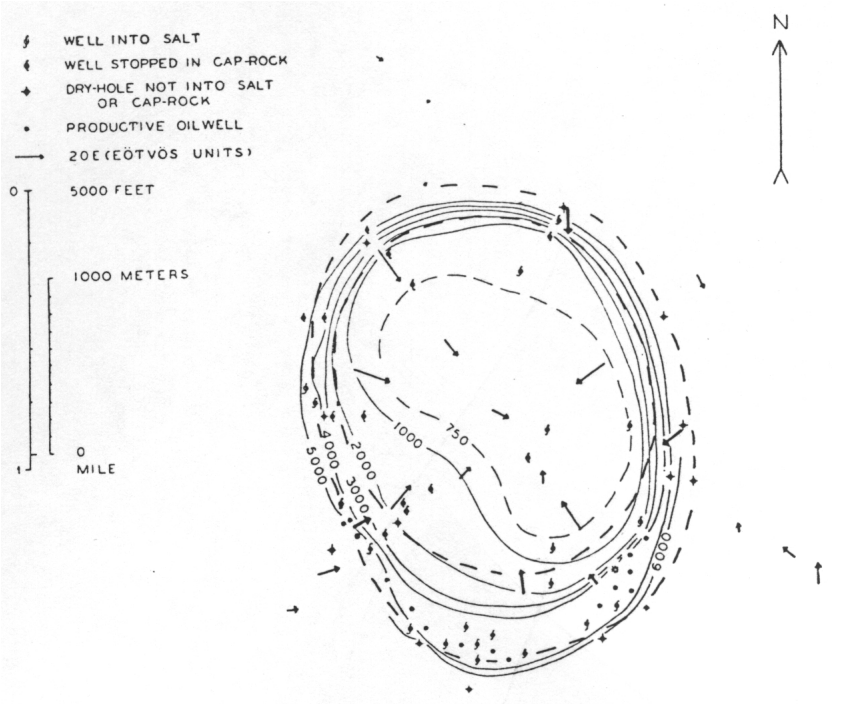

Figure 3. The first hydrocarbon prospect, the Nash Dome, located with geophysics in the United States. This prospect was identified by the distinctive suite of arrows pointing toward the center of dense caprock atop the salt dome (from "The Eötvös torsion balance method of mapping geologic structure" by D. C. Barton, Geophysical Prospecting, 1929).
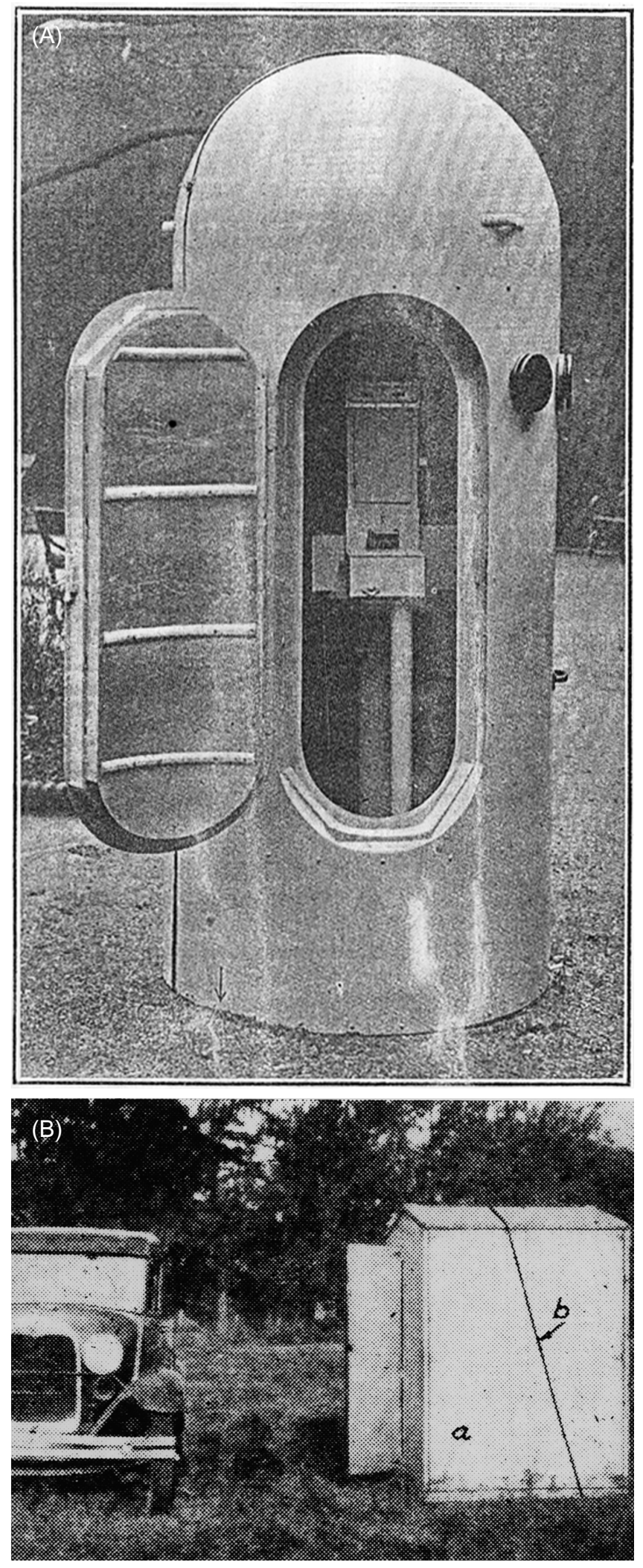

Figure 4. Two field enclosures used with torsion-balance gradiometers: (a) dome-like structure used in Britain (from "The theory and practical use of the Eötvös Torsion Balance" by Shaw and LancasterJones, Mining Magazine, 1927) and (b) cloth-sided shelter used widely in the U.S. Gulf Coast with a Model T for scale (from Exploration Geophysics by J. J. Jakosky, 1940). 


\section{GEOPHYSICAL ACTIVITY IN GULF OF MEXICO}

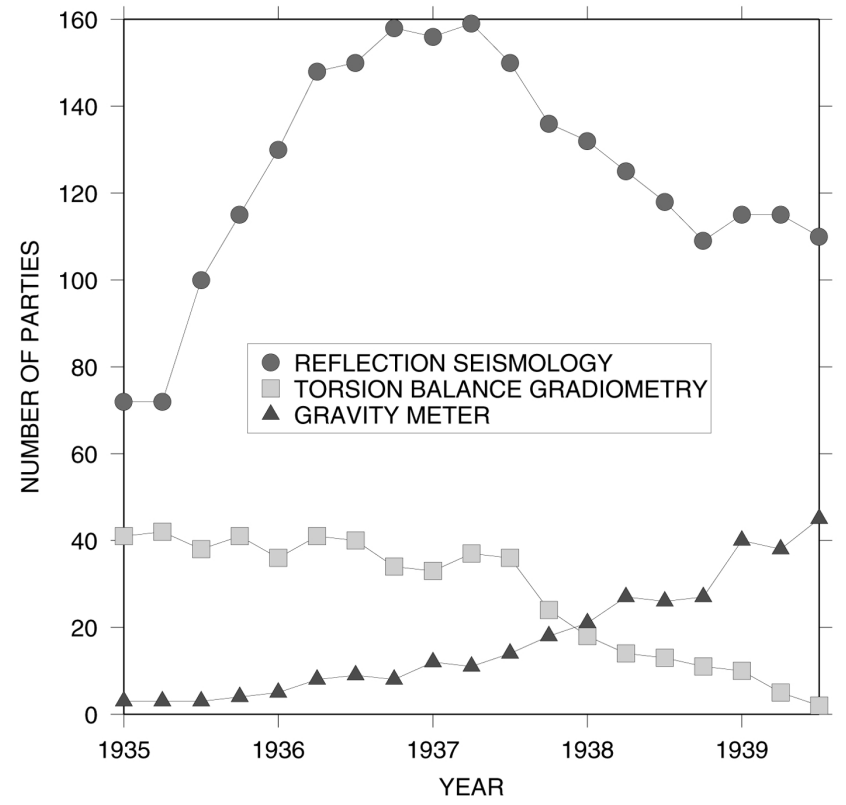

Figure 5. The transition from torsion-balance gradiometry to gravity measurements during the 1930s in the Gulf Coast region. The plot shows the number of geophysical field parties active during each quarter from 1935 to 1939 (from "A brief history of the gravity method of prospecting for oil" by E. A. Eckhart, GEOPHYSICS, 1940).

a beautifully simple circle of arrows pointing toward the center of the dome (Figure 3). The geophysical exploration industry was born in the United States.

A long string of successes followed, and contracting companies appeared almost immediately. For a time, the torsion balance had no competition whatsoever in the search for oil and gas. In the next 10 or so years, the discovery of more than 1 billion barrels of oil and at least 79 producing structures was attributed to the application of this instrumentation.

The instruments generally were about $2 \mathrm{~m}$ in height and were isolated from the elements by a collapsible building resembling an outhouse or a large tent (Figure 4). The most advanced design required 20 minutes for an individual reading, a significant improvement over the several hours that earlier designs needed. Unfortunately, the ground surrounding a torsion-balance measurement had to be leveled in eight directions, often out to $100 \mathrm{~m}$. This obviously took a lot of time, and the resulting star-shaped pattern left in vegetated areas never would have passed today's environmental regulations. This leveling to reduce near-zone terrain effects and erecting the shelter meant that each station required, at the least, a few hours to observe. The instrument was very sensitive to near effects including belt buckles and metal in the observer's pockets (!), old cellar holes, and overhead wires. Despite these complications, measurements were excellent quality even by today's standards (resolution of about 1 Eötvös).

Interpretive tools for gradiometry data were slow to develop. The early identification of salt domes and cap rocks was strikingly simple - arrows resulting from the data pointed toward the salt dome. However, these arrows became difficult to interpret over more complex structures. Despite arguments in the literature about developing tools and visualizations which used all the gradient data recorded, the measurements were increasingly integrated into gravity maps. This failure to develop interpretive tools would contribute to the marginalization of gradiometry.

By the late 1920s refraction seismology appeared on the scene. Reflection seismology followed soon after. Curiously, the perceived roles of gravity and seismology were very similar to those of today, with gravity recommended for reconnaissance work and seismology for detailed follow-up. This assignment of responsibility was also as controversial as it is today.

The year 1930 brought both the Great Depression and the initial field deployment of pendulum gravity meters. Although awkward to use and not very accurate, the pendulum gravity meter was significantly faster than the torsion balance and yielded quantities which most geologists found easier to interpret. The trend of integrating the gravity gradient readings to give results which could be directly compared with the gravity meter continued. Finally, in the mid-1930s, the first modern astatized spring gravity meters appeared. These were much smaller and more accurate than the pendulum meter, and much faster and less sensitive to near-zone terrain than the torsion balance. This last feature made the new meters useful in terrain where the torsion balance did not give usable results. The new meters rapidly supplanted the torsion balance in U.S. oil exploration (Figure 5); despite the protests of some who claimed that the new instrument had "lower resolving power," the torsion balance was a museum piece in the United States by 1940, although its use lingered on in eastern Europe for much longer.

However, the use of gradient measurements never disappeared completely. Through the 1950s and 1960s enterprising geophysicists attempted numerous experiments, mostly with vertical gradiometers synthesized from paired gravimeter measurements. Most of these experiments were aimed at mineral or geotechnical applications. Finally in the late 1960s came the realization that gradiometers had great potential in moving-platform applications because of the absence of vertical heave and Eötvös errors, and the modern era of gradiometers was born. Today the development of interpretive tools for gradiometry data is the challenge of a new era of grdliometry .

Corresponding author: Robin Bell, phone 914-365-8827. 